Research Article

\title{
Study on the Dynamic Deformation of Road High Liquid Limit Subgrade Soil
}

\author{
Zheng Lu $\mathbb{D}^{1,2}$ Ran Fang, ${ }^{3}$ Yongxiang Zhan $\mathbb{D}^{1},{ }^{1}$ and Hailin Yao ${ }^{1}$ \\ ${ }^{1}$ State Key Laboratory of Geomechanics and Geotechnical Engineering, Institute of Rock and Soil Mechanics, \\ Chinese Academy of Sciences, Wuhan 430071, China \\ ${ }^{2}$ Hubei Key Laboratory of Geo-Environmental Engineering, Wuhan 430071, China \\ ${ }^{3}$ University of Chinese Academy of Sciences, Beijing 100049, China \\ Correspondence should be addressed to Zheng Lu; lzwhrsm@163.com
}

Received 7 November 2018; Accepted 14 May 2019; Published 28 May 2019

Academic Editor: Fan Gu

Copyright (C) 2019 Zheng Lu et al. This is an open access article distributed under the Creative Commons Attribution License, which permits unrestricted use, distribution, and reproduction in any medium, provided the original work is properly cited.

\begin{abstract}
In order to evaluate the traffic-load-induced cumulative deformation of road high liquid limit subgrade soil, a series of laboratory tests are performed to determine the physical and mechanical properties of high liquid limit soil. A cumulative deformation model is then developed with consideration of the effects of dynamic deviator stress, the number of repeated loadings, and the material properties of subgrade soil. Based on Lu's vehicle-road-ground coupling model, the traffic-load-induced stress, which is very important in predicting cumulative settlement of the subgrade, is calculated explicitly. The layerwise summation method is used to evaluate the traffic-load-induced cumulative deformation. Moreover, a parametric study is conducted using numerical computation and the results show that the traffic-load-induced cumulative deformation is mainly generated from the shallow soil, and the additional dynamic load plays an important role in analyzing the traffic-load-induced settlement.
\end{abstract}

\section{Introduction}

With the rapid development of high-speed traffic in China, many engineering problems about high liquid limit soils are sprouting out, which provides great developmental momentum and severe challenges for the further study of high liquid limit soil or its related engineering. High liquid limit soil is a kind of special soil which often expresses some characteristics including high natural water content, high porosity ratio, low permeability, low strength, and high compressibility. Spring soil phenomenon and inhomogeneous compaction have effects on the quality of embankment construction just because the water in soil is difficult to evaporate. When subjected to moving traffic loads, the dynamic response and deformation performances of the high liquid limit soil subgrade have large differences with a traditional subgrade compacted by sandy soils or gravels or artificial filling materials [1-5]. This is due to the fact that the high liquid limit soil has distinctive features of high compressibility, disintegrating, softening by absorbing water, shrinking and cracking by losing water, and repeated changing.

For a road subgrade compacted by high liquid limit soils, the cumulative plastic deformation of the subgrade due to vehicle traffic load is one of the important factors that control the long-term service life as well as the maintenance cost of the road. Therefore, it is essential to predict the traffic-load-induced cumulative deformation so as to carry traffic safely, conveniently, and economically during its entire lifespan. Some scholars carried out research on the subgrade soil cumulative deformation caused by repeated loading based on experiments [6-12], which make it possible to derive empirical relationships of cumulative deformation with the number of applied load cycles. Although this method is simple, the dynamic characteristics of soils are not taken into consideration, and the traffic-load-induced stress is not calculated explicitly. By introducing different elastoplastic material models, several researchers developed numerical methods such as the finite element method (FEM) $[13,14]$, the moving element method (MEM) [15], the 
boundary element method (BEM) [16], and the FEM/BEM hybrid scheme $[17,18]$ to study the deformation behavior of subgrade soils subjected to cyclic loads. Theoretically, explicit simulation is preferable. However, it would consist of implementing a conventional step-by-step elastoplastic procedure, requiring the discretization of each individual load cycle into a sufficiently small number of cycles, which will quite rapidly lead to considerable computational time and complete loss of numerical accuracy as the number of cycles increase.

The objective of this work is therefore to evaluate the traffic-load-induced cumulative deformation of road high liquid limit subgrade soil. In this paper, laboratory tests on high liquid limit soil are carried out to derive the calculation parameters. Then a cumulative deformation model is developed with consideration of the effects of dynamic deviator stress, the number of repeated loadings, and the material properties of subgrade soil. In case of an uneven pavement, a more realistic vehicle-road-ground coupling model proposed by $\mathrm{Lu}$ et al. [19] is employed to calculate the trafficload-induced dynamic deviator stress in subgrades. The layerwise summation method is used to evaluate the trafficload-induced cumulative deformation, and a parametric study is conducted to consider the influences of types of loads and the different depths on the cumulative deformation using numerical computation.

\section{Laboratory Tests on High Liquid Limit Soil}

2.1. Physical Property Tests. The soil specimens used in this experiment are taken from the soil sampling site at K281 section of Laibin-Mashan expressway in Guangxi, China. The subsoil in this area is the high liquid limit red clay, and the basic physical parameters are shown in Table 1. As can be seen from the table, the particle composition of the red clay is characterized by fine particles, of which the content of clay particles is the main component of the particles. Red clay possess the properties of typical high liquid limit soil due to the high natural water content that is over than saturated state, the liquid limit is more than $50 \%$, and the plasticity is very strong.

2.2. Mechanical Property Tests. In order to study the road performance of compacted red clay, three-axis shear tests under different compaction degrees are carried out to determine the shear strength index of compacted soil and provide the parameters for subsequent related calculations. According to the characteristics of embankment construction and postoperation, the consolidation undrained triaxial tests are adopted in the experiment under three different compaction degrees of $96 \%, 93 \%$, and $90 \%$, which corresponding to the dry density value is $1.40,1.45$, and $1.50 \mathrm{~g} / \mathrm{cm}^{3}$, respectively. Figure 1 shows the stress-strain curves of test soil with compaction degree of $96 \%$. It can be seen from the figure that the principal stress difference of soil samples with different confining pressures increases initially with the increase of axial strain and then tends to be stable. The stress-strain curves for four confining pressures indicate strain hardening up to the maximum of $20 \%$ axial strain, behaving as the characteristics of plastic failure. This result may be related to the coupling effect of compaction degree and moisture content of the red clay, which indicates that the soil grains can easily be sticking together and there are no obvious shear bands in the test samples under the condition of higher moisture contents. Based on the Mohr-Coulomb strength principle, Mohr stress circle and soil strength envelope at different stress levels can be obtained, as shown in Figure 2.

In addition, the consolidation undrained triaxial tests are carried out in terms of the remolded samples and undisturbed samples, and the test results are shown in Table 2. It can be found that the cohesion of the red clay is $53.1 \mathrm{kPa}$ in its natural state, similar to the remolded state with the compaction degree of $90 \%$, and soil cohesion will increase in some extent after increasing the compaction degree, for example, if the compaction degree of remolded sample is $96 \%$, the cohesion increases by about $18 \%$. However, the internal frictional angles of the remolded red clay samples with three different compaction degrees have no significant difference. The initial compaction state can significantly affect the cohesion of the soil, which indicates that the compaction of the red clay subgrade contributes mainly to the strength of the subgrade soil through increasing its cohesion. The nature of the increase of soil cohesion is caused by the physicochemical interactions between moisture and clay particles in which the bound water forms a liquid film among the particles. The original cohesion of the soil is taken as the cohesive structure due to the presence of bound moisture that leads to it. However, the stability of the original cohesion of the soil is poor, and it decreases as the water content of the soil increases because the increase of water actually thickens the water film thickness between the particles. It is an ancient and effective mechanical disposal method to increase the strength of soil by compaction that increases soil compaction to raise the number of contact points and decrease the liquid membrane thickening space, resulting in enhancing cohesion and strength of soil.

\section{Cumulative Deformation of High Liquid Limit Subgrade Soil}

For high-speed railways and expressways, it is critical to control the settlement of subgrade after construction very strictly, while the subgrade receives millions of times of repeated traffic loads during the operation period, and the cumulative settlement is unavoidable. Therefore, how to evaluate the cumulative deformation of compacted soil caused by traffic load is very important. Monismith first put forward an index model of cumulative plastic strain of soil [20]. Then, Li and Selig proposed the formula [21] for calculating the cumulative plastic strain of foundation soils by considering the deviatoric stress and static failure stress:

$$
\varepsilon_{\mathrm{p}}=a\left(\frac{\sigma_{\mathrm{d}}}{\sigma_{\mathrm{f}}}\right)^{m} N^{b}
$$

where $\varepsilon_{\mathrm{p}}$ is the cumulative plastic strain of the soil; $N$ is the number of cycles of dynamic loading; $a, b$, and $m$ are the 
TABLE 1: Physical parameters of red clay.

\begin{tabular}{lccccccc}
\hline$<0.005 \mathrm{~mm}$ particle content (\%) & $\begin{array}{c}\text { Natural moisture } \\
\text { content (\%) }\end{array}$ & Density $\left(\mathrm{g} / \mathrm{cm}^{3}\right)$ & Void ratio & $\begin{array}{c}\text { Saturation } \\
(\%)\end{array}$ & $\begin{array}{c}\text { Liquid limit } \\
(\%)\end{array}$ & $\begin{array}{c}\text { Plastic } \\
\text { limit }(\%)\end{array}$ & $\begin{array}{c}\text { Plasticity } \\
\text { index }\end{array}$ \\
\hline 62 & 58 & 1.68 & 1.46 & 106.6 & 73 & 41 & 32 \\
\hline
\end{tabular}

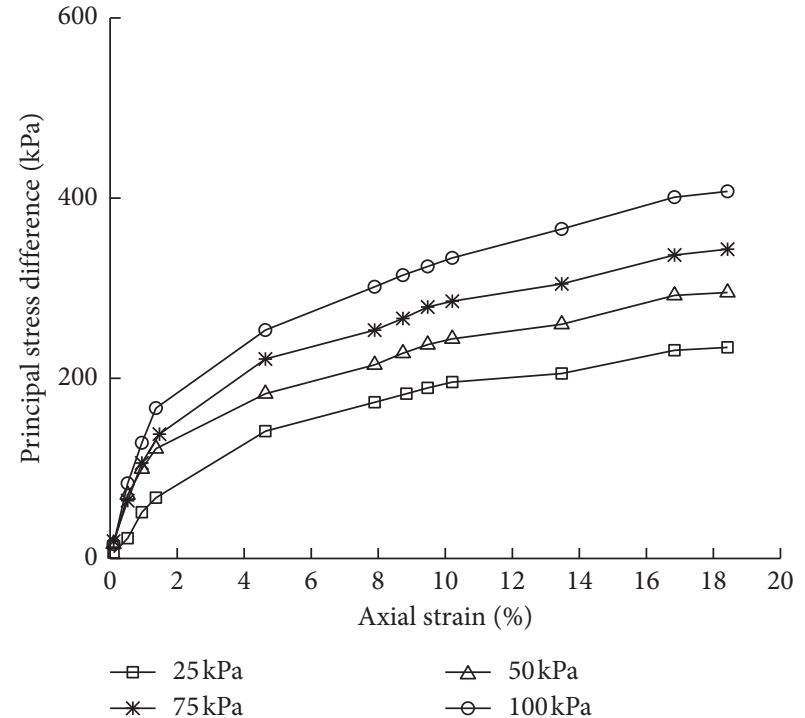

Figure 1: Stress-strain curve of $96 \%$ compaction.

parameters related to the soil type and plasticity index; and $\sigma_{\mathrm{d}}$ and $\sigma_{\mathrm{f}}$ are the dynamic deviator stress and static failure stress, respectively.

Based on equation (1), considering the dynamic load of moving vehicles and the stratification of the subgrade system, the cumulative settlement of the compacted subgrade is

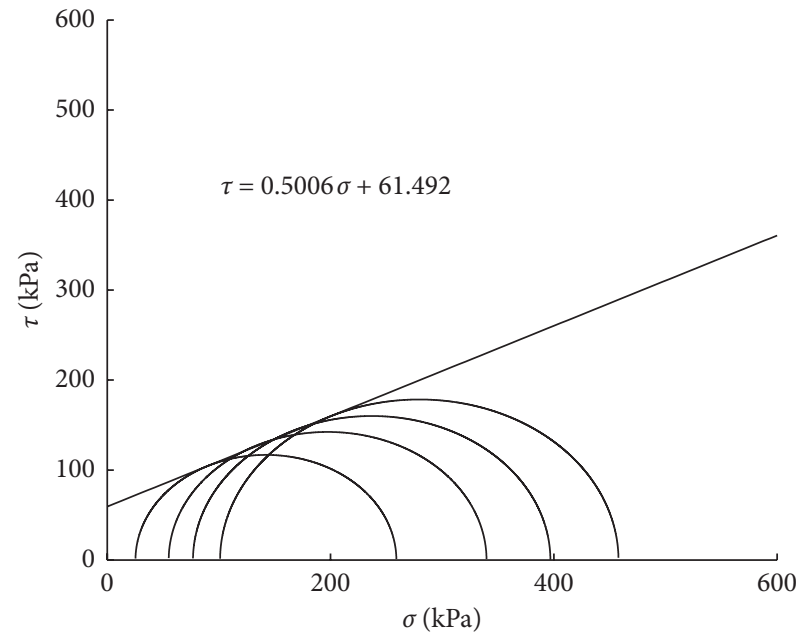

FIgURE 2: Strength envelope of compacted soil.

obtained by employing the stratified summation method, and the calculation steps are shown as below.

3.1. Calculating the Deviatoric Stress Caused by Traffic Load. The relationship between the dynamic deviatoric stress of the subgrade and the stress component caused by traffic load shown in

$$
\sigma_{\mathrm{d}}=\sqrt{3 J_{2}}=\sqrt{\frac{1}{2}\left[\left(\sigma_{x x}-\sigma_{y y}\right)^{2}+\left(\sigma_{x x}-\sigma_{z z}\right)^{2}+\left(\sigma_{y y}-\sigma_{z z}\right)^{2}+6\left(\tau_{x z}^{2}+\tau_{y z}^{2}+\tau_{x y}^{2}\right)\right]},
$$

where $J_{2}$ is the second invariant of the dynamic deviatoric stress and $\sigma_{x x}, \sigma_{y y}, \sigma_{z z}, \tau_{x z}, \tau_{y z}$, and $\tau_{x y}$ are the six stress components of the subgrade. To estimate the value of $\sigma_{\mathrm{d}}$, the $3 \mathrm{D}$ traffic-load transfer mechanism and the characteristics of a multilayered road structure must be considered. Also, it has been proved that the dynamic load generated from coupled vehicle-uneven pavement vibration made a significant contribution to the traffic-induced stress components in the ground $[19,22]$. Thus, the effect of pavement unevenness must also be considered in prediction of the traffic-induced stresses. Lu's vehicle-road-ground coupling model and dynamic response solution [19] are considered suitable for this purpose.

3.2. Calculating the Static Failure Stress of Compacted Soil. The static failure stress of cohesive soil can be obtained:

$$
\sigma_{\mathrm{f}}=2 \tau_{\mathrm{f}},
$$

where $\sigma_{\mathrm{f}}$ is the static failure stress of soil and $\tau_{\mathrm{f}}$ is the undrained shear strength of soil, which can be calculated with the undrained total stress intensity index $c_{\mathrm{cu}}$ and $\varphi_{\mathrm{cu}}$.

According to the theory of effective consolidation stress, clay is taken as a pure cohesive material. The angle between the direction of rupture and principal stress is 45 degrees. The corresponding strength formula is [23]

$$
\tau_{\mathrm{f}}=c_{\mathrm{c}}+\frac{1}{2}\left(\sigma_{1 \mathrm{c}}^{\prime}+\sigma_{3 \mathrm{c}}^{\prime}\right) \tan \varphi_{\mathrm{c}}
$$

where $\sigma_{1 \mathrm{c}}^{\prime}$ and $\sigma_{3 \mathrm{c}}^{\prime}$ are effective consolidation stress and $\tau_{\mathrm{f}}$ is the total shear strength, which can generally be calculated by the consolidation undrained triaxial index $c_{\mathrm{cu}}$ and $\varphi_{\mathrm{cu}}$, as shown below:

$$
\tau_{\mathrm{f}}=c_{\mathrm{cu}} \cos \varphi_{\mathrm{cu}}+\frac{1}{2}\left(\sigma_{1 \mathrm{f}}+\sigma_{3 \mathrm{f}}\right) \sin \varphi_{\mathrm{cu}}
$$

where $\sigma_{1 \mathrm{f}}$ and $\sigma_{3 \mathrm{f}}$ are the effective principal stresses at failure; in actual engineering, the subgrade soil is in the state 
TABle 2: Strength parameters of the red clay under different compaction degrees.

\begin{tabular}{lcccc}
\hline & \multicolumn{4}{c}{ Remoulded samples } \\
\hline & \multicolumn{3}{c}{ Compaction } \\
degree (\%) & Undisturbed samples \\
Strength parameter & $\begin{array}{c}90 \\
\text { Degree of }\end{array}$ & 96 \\
& saturation (\%) & Degree of saturation (\%) \\
& 71.5 & 77 & 83 & 106.6 \\
\hline $\begin{array}{l}\text { Internal friction } \\
\text { angle }\left(^{\circ}\right)\end{array}$ & 26.2 & 26.3 & 26.6 & 27.6 \\
\hline Cohesion $(\mathrm{kPa})$ & 52.2 & 58.6 & 61.5 & 53.1 \\
\hline
\end{tabular}

of $K_{0}$ consolidation. Assuming that the maximum principal stress is self-weighting stress, corresponding to the triaxial test, the soil samples are firstly consolidated by $K_{0}$, $\sigma_{3 \mathrm{c}}^{\prime}=K_{0} \sigma_{1 \mathrm{c}}^{\prime}$. When increasing $\sigma_{1}$ to destroy it, $\sigma_{3 \mathrm{f}}=$ $\sigma_{3 \mathrm{c}}^{\prime}+2 \tau_{\mathrm{f}}$, using equations (4) and (5), the following relation is obtained:

$$
\tau_{\mathrm{f}}=\frac{c_{\mathrm{cu}} \cos \varphi_{\mathrm{cu}}}{\left(1-\sin \varphi_{\mathrm{cu}}\right)}+\frac{\left(1+K_{0}\right) \sigma_{\mathrm{cz}} \sin \varphi_{\mathrm{cu}}}{\left(1-\sin \varphi_{\mathrm{cu}}\right)},
$$

where $K_{0}$ is the soil lateral limit coefficient and $\sigma_{\mathrm{cz}}$ is the soil self-weight stress. Employing equation (6), one can obtain undrained shear strength formula with the consolidation undrained test, and the static failure stress of cohesive soil can be calculated by using equation (3).

3.3. Determining Parameters $a, b$, and $m$. The accurate parameters can be obtained through the indoor triaxial test or field vibration test. Fit $a$ and $m$ with the relation curve of first cyclic plastic strain and deviatoric stress with the first loading test under different deviatoric stress levels. Then fit the curve of cumulative cyclic strain and the corresponding first cycle plastic strain to obtain $b$. Li and Selig proposed the parameters $a, b$, and $m$ as shown in Table 3 [21] through dynamic triaxial tests with different silts and clays. The second part of the experiment shows that the test soil in this paper is a typical high liquid limit clay. Therefore, the data in Table 3 can be used for subsequent analysis.

\subsection{Calculating the Cumulative Plastic Strain of the Subgrade.} Based on the above research, the compacted subgrade is stratified thinly (for example, $0.1 \mathrm{~m}$ per layer), and the cumulative plastic strain of each layer of the subgrade is calculated by the strain model of equation (1).

\subsection{Determining the Cumulative Plastic Deformation of the} Subgrade. After obtaining the cumulative plastic strain of the each layer, the total cumulative plastic deformation can be calculated by the stratified summation method:

$$
S_{\mathrm{P}}=\sum_{i=1}^{n} \varepsilon_{\mathrm{p} i} h_{i},
$$

where $S_{\mathrm{P}}$ is the total cumulative plastic deformation of the subgrade, $\varepsilon_{\mathrm{p} i}$ is the cumulative plastic strain of the $i$ th soil, $h_{i}$ is the thickness of the $i$ th soil, and $n$ is the total layer number of subgrade. Combining equations (1) and (7), the cumulative plastic deformation model of the high liquid soil subgrade under traffic load can be obtained:

$$
S_{\mathrm{P}}=\sum_{i=1}^{n}\left[a_{i}\left(\frac{\sigma_{\mathrm{d}_{i}}}{\sigma_{\mathrm{f}_{i}}}\right)^{m_{i}} N^{b_{i}}\right] h_{i} \text {. }
$$

It has been proven that the dynamic deviator stress is crucial in predicting the traffic-induced permanent deformation of the road subgrade, which is an important factor that controls the service life and maintenance costs of the road. Therefore, it is desirable to investigate the dynamic deviator stress firstly. In this section, the 20-ton heavy truck with a speed $V=80 \mathrm{~km} / \mathrm{h}$ is considered. The parameters of pavement unevenness are fixed at $\lambda=12 \mathrm{~m}$ and $A=2 \mathrm{~mm}$. The thickness of pavement is $0.5 \mathrm{~m}$, and the elastic modulus and Poisson's ratio are $1200 \mathrm{MPa}$ and 0.25 , respectively. Other parameters are the same as Lu et al. [19]. Both of the axle load and the additional dynamic load are considered.

Figure 3 shows the distributions of the dynamic deviator stress at different depths of the subgrade caused by the axle load. It can be found from the figure that the dynamic deviator stress at different depths is basically symmetrical along the $x=0$ axis. As the depth increases, the dynamic deviator stress of the subgrade rapidly decreases, and the influence range of the dynamic deviator stress in the moving direction of the vehicle is limited to the range of $-4 \mathrm{~m}<x<4 \mathrm{~m}$. Beyond this range, the dynamic deviator stress is small. In order to show the contribution of the additional dynamic load, Figure 4 presents the distributions of the dynamic deviator stress caused by the axle load and the additional dynamic load, respectively, at the top of the subgrade. It can be seen from the figure that the maximum dynamic deviator stress at the top of the subgrade of $20 \mathrm{t}$ heavy truck induced by the axle load can reach $35.8 \mathrm{kPa}$ and the maximum dynamic deviator stress generated by the additional dynamic load is $6.2 \mathrm{kPa}$. The proportions of total dynamic deviator stress are $85.2 \%$ and $14.8 \%$, respectively.

Figure 5 shows the variations of the dynamic deviator stress with subgrade depth. It can be seen that the dynamic deviator stress decreases rapidly with the increase of the depth. In the shallow region $(0 \mathrm{~m}<x<1 \mathrm{~m})$ of the subgrade, the dynamic deviator stress decreases very rapidly; as the depth increases $(1 \mathrm{~m}<x<3 \mathrm{~m})$, the decay of the deviator stress becomes slow. It is predictable that the cumulative plastic deformation of the subgrade caused by traffic load will be mainly produced by shallow soil.

Based on the laboratory tests on high liquid soil and the abovementioned prediction model, the cumulative plastic strain, and cumulative deformation of the subgrade can be calculated and analyzed. In the calculation, the cohesion of compacted soil is $61.5 \mathrm{kPa}$ and the internal friction angle is 26.6 according to Section 2. Material parameters $a, b$, and $m$ are taken as $1.20,0.18$, and 2.40 , respectively. Figures $6-8$ show some of the results.

Providing that the traffic loads move along the centreline of the road, Figure 6 presents the distributions of 
TABle 3: Different soil material parameter values.

\begin{tabular}{lcccc}
\hline Parameters & Low liquid limit silt & High liquid limit silt & Low liquid limit clay & High liquid limit clay \\
\hline$a$ & 0.64 & 0.84 & 1.10 & 1.20 \\
$b$ & 0.10 & 0.13 & 0.16 & 0.18 \\
$m$ & 1.70 & 2.00 & 2.00 & 2.40 \\
\hline
\end{tabular}

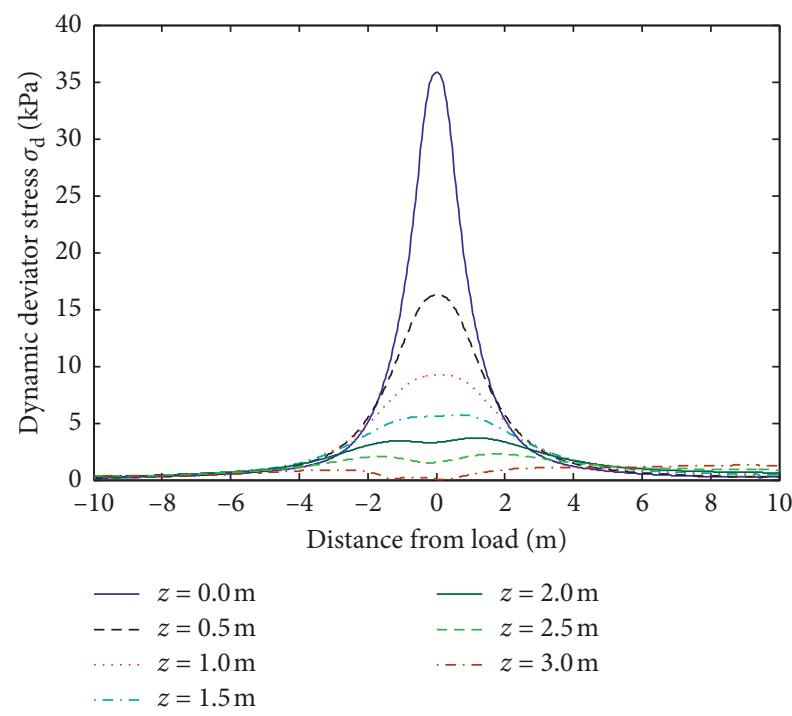

FIGURE 3: Distributions of the dynamic deviator stress $\sigma_{\mathrm{d}}$ caused by the axle load.

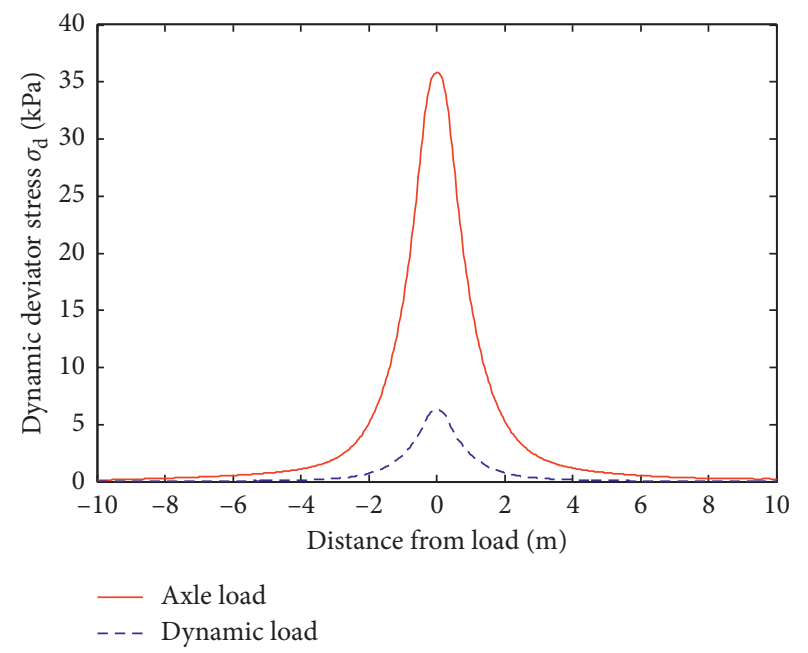

FIGURE 4: Distributions of the dynamic deviator stress $\sigma_{\mathrm{d}}$ at the subgrade top surface.

cumulative plastic strain of crossroad profile after ten million cycles, where different depths including $0.0,0.25$, $0.5,0.75$, and $1.0 \mathrm{~m}$ below the subgrade surface are considered. It can be seen from the figure that the distribution law of cumulative plastic strain along the moving direction is similar to the dynamic stress distribution law, as shown in Figure 3. The cumulative plastic strain at the top of the subgrade is the largest; as the depth increases, the cumulative plastic strain decreases gradually. At depth

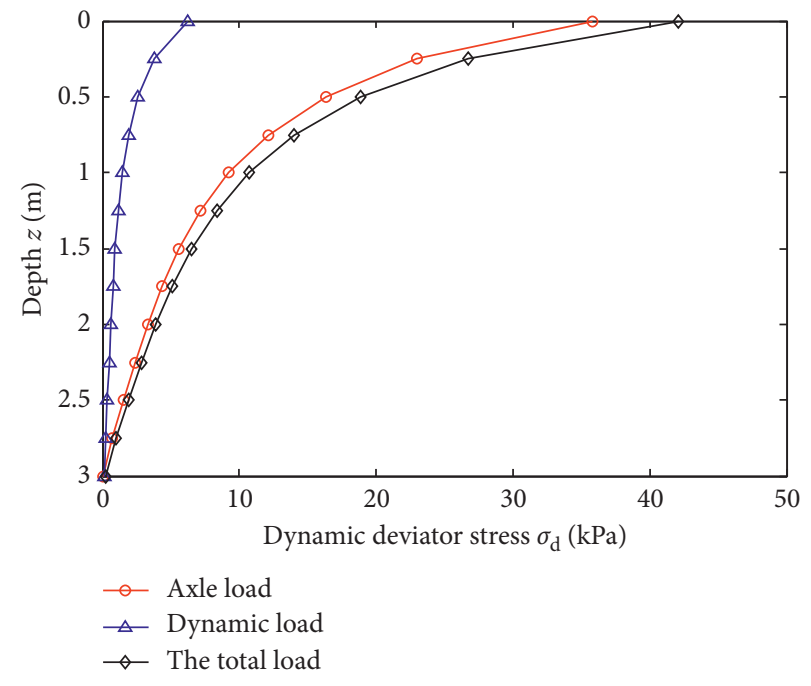

Figure 5: Variations of the dynamic deviator stress $\sigma_{\mathrm{d}}$ with depth.

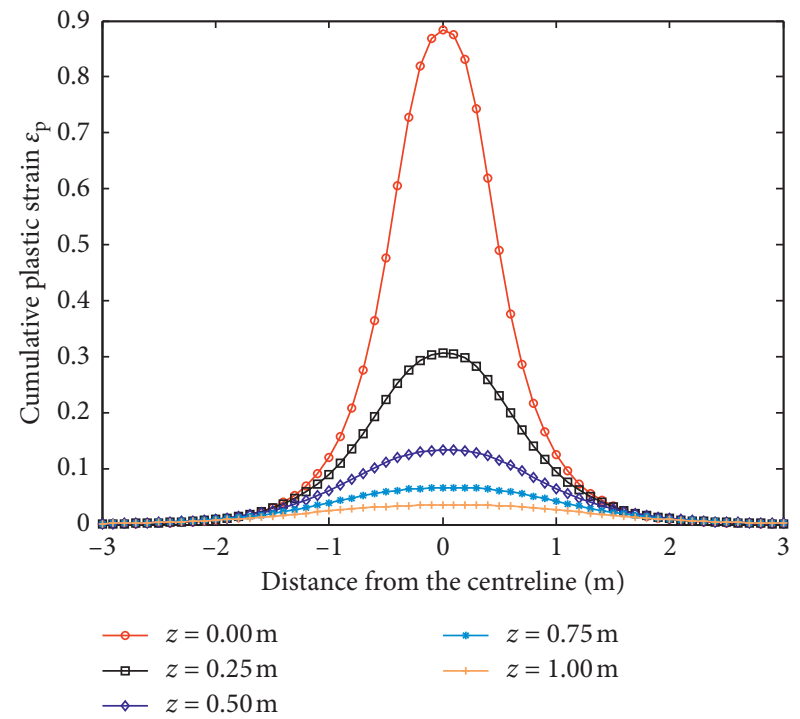

Figure 6: Distributions of cumulative plastic strain $\varepsilon_{\mathrm{p}}$ after ten million cycles.

$z=1.0 \mathrm{~m}$, the maximum cumulative plastic strain is only $0.03 \%$, which is significantly smaller than that of the subgrade surface. This indicates that the traffic-loadinduced cumulative deformation is mainly generated by the superficial layer of the subgrade within $0 \sim 1 \mathrm{~m}$. In addition, it can also be seen from Figure 6 that the distribution of cumulative plastic strain with the horizontal direction is concentrated in the range of $-1 \mathrm{~m}<x<1 \mathrm{~m}$, beyond which the cumulative plastic strain is small. This 


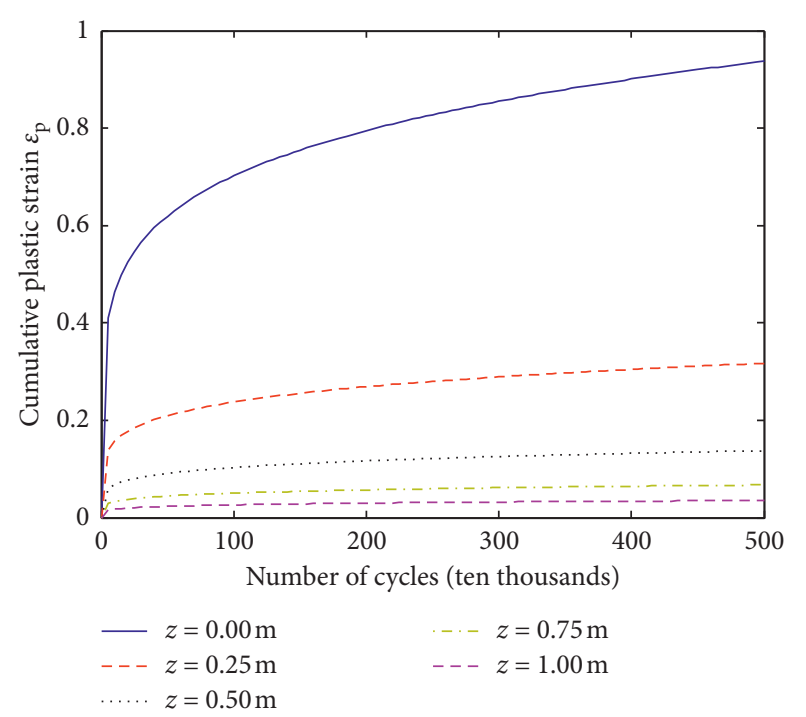

Figure 7: Development of cumulative plastic strain $\varepsilon_{\mathrm{p}}$ with the number of cycles.

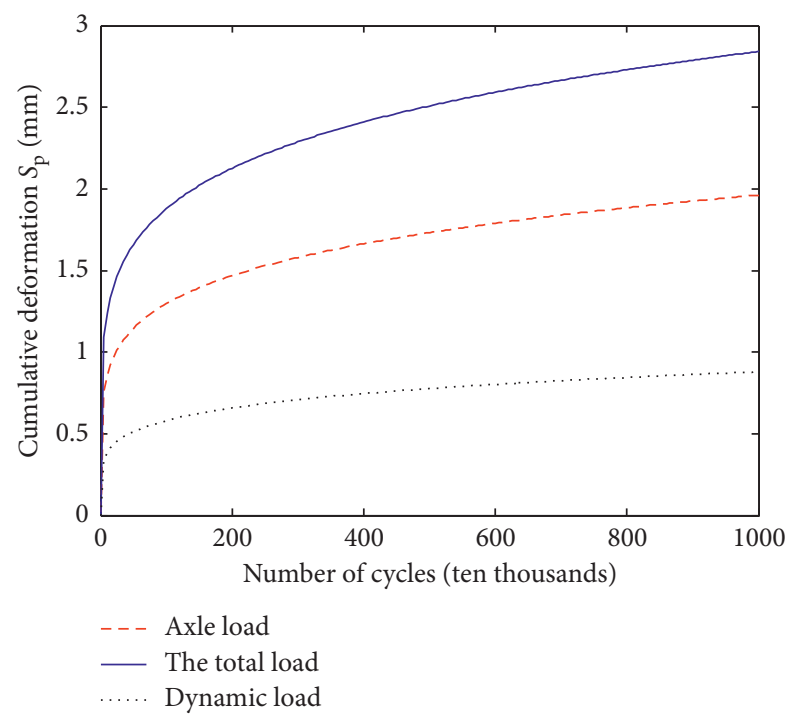

Figure 8: Development of cumulative deformation $S_{\mathrm{p}}$ with the number of cycles.

demonstrates that after opening to traffic for many years, there will be obvious settlement directly below the tire of the traffic lane, and the settlement near the shoulder of the road, which is seldom affected by tire repetition, will be small, resulting in the uneven settlement of the entire road cross section.

Figure 7 shows the development of cumulative plastic strain with the number of loading cycles for different subgrade depths. It can be seen from Figure 7 that the curves for different subgrade depths exhibit the same tendency. The cumulative plastic strain grows quickly initially, but the speed of increase becomes gradually slower. Figure 8 presents the distributions of cumulative deformation with the number of repeated loading cycles at the subgrade surface. The different contributions of the axle load and additional dynamic load to the cumulative deformation are also investigated in Figure 8. As can be seen from the figure that the total cumulative plastic deformation of the subgrade can reach $2.84 \mathrm{~mm}$ after ten million loading cycles, and the percents of the axial loadinduced cumulative plastic deformation and additional dynamic load-induced one in the total deformation are $69 \%$ and $31 \%$, respectively. This result implies that the additional dynamic load generated from coupled vehiclepavement vibration plays an important role in the trafficinduced cumulative plastic deformation in the subgrade and should not be neglected when predicting the trafficinduced settlement.

\section{Conclusions}

In this paper, the traffic-load-induced deformation of road high liquid limit subgrade soil is investigated. The main conclusions of this study can be summarized as follows:

(1) The additional dynamic load generated from coupled vehicle-pavement vibration plays an important role for the traffic-induced deviator stress in the subgrade and should not be neglected when predicting the traffic-load-induced deformation.

(2) The values of cumulative strain of different depths decrease sharply along the horizontal direction and then gradually decrease to zero when far away from the road centreline by more than $3 \mathrm{~m}$. This indicates that after opening to traffic for many years, there will be obvious settlement directly below the tire of the traffic lane, and the settlement near the shoulder of the road, which is seldom affected by tire repetition, will be small, resulting in the uneven settlement of the entire road cross section.

(3) After 10 million cycles of loading, the total cumulative plastic deformation of the subgrade can reach $2.84 \mathrm{~mm}$, and the percents of the axial load-induced cumulative plastic deformation and additional dynamic load-induced one in the total deformation are $69 \%$ and $31 \%$, respectively.

\section{Data Availability}

The data used to support the findings of this study are available from the corresponding author upon request.

\section{Conflicts of Interest}

The authors declare that they have no conflicts of interest.

\section{Acknowledgments}

This work was supported by the Youth Innovation Promotion Association CAS (2015270), the outstanding youth fund of Hubei Province (2017CFA056), and the Science and Technology Service Network Initiative of CAS (KFJ-STSZDTP-037). 


\section{References}

[1] N. Z. Guo, J. F. Zou, L. Li, and X. L. Yang, "Dynamic compaction theory and experiments in high roadbed filled with red sandstone," Journal of Central South University: Science and Technology, vol. 39, no. 1, pp. 185-189, 2008.

[2] J. Li, J. Zhang, G. Qian, J. Zheng, and Y. Zhang, "Threedimensional simulation of aggregate and asphalt mixture using parameterized shape and size gradation," Journal of Materials in Civil Engineering, vol. 31, no. 3, article 04019004, 2019.

[3] Y. Cai, Q. Sun, L. Guo, C. H. Juang, and J. Wang, "Permanent deformation characteristics of saturated sand under cyclic loading," Canadian Geotechnical Journal, vol. 52, no. 6, pp. 795-807, 2015.

[4] E. A. Basha, R. Hashim, H. B. Mahmud, and A. S. Muntohar, "Stabilization of residual soil with rice husk ash and cement," Construction and Building Materials, vol. 19, no. 6, pp. 448453, 2005.

[5] X. Tan, W. Chen, H. Liu, and A. H. C. Chan, "Stress-strain characteristics of foamed concrete subjected to large deformation under uniaxial and triaxial compressive loading," Journal of Materials in Civil Engineering, vol. 30, no. 6, article 04018095, 2018.

[6] Q. Sun, Y. Cai, J. Chu, Q. Dong, and J. Wang, "Effect of variable confining pressure on cyclic behaviour of granular soil under triaxial tests," Canadian Geotechnical Journal, vol. 54, no. 6, pp. 768-777, 2017.

[7] K. Fujikawa, N. Miura, and I. Beppu, "Field investigation on the settlement of low embankment due to traffic load and its prediction," Soils and Foundations, vol. 36, no. 4, pp. 147-153, 1996.

[8] J.-C. Chai and N. Miura, "Traffic-load-induced permanent deformation of road on soft subsoil," Journal of Geotechnical and Geoenvironmental Engineering, vol. 128, no. 11, pp. 907-916, 2002.

[9] A. Joseph and M. James, "Permanent deformation testing for a new South African mechanistic pavement design method," Construction and Building Materials, vol. 26, pp. 541-546, 2012.

[10] Y. Q. Cai, L. Guo, R. J. Jardine, Z. X. Yang, and J. Wang, "Stress-strain response of soft clay to traffic loading," Géotechnique, vol. 67, no. 5, pp. 446-451, 2017.

[11] J. Zhang, J. Peng, J. Zheng, and Y. Yao, "Characterisation of stress and moisture-dependent resilient behaviour for compacted clays in South China," Road Materials and Pavement Design, vol. 19, pp. 1-14, 2018.

[12] J. H. Zhang, J. Peng, J. Zheng, L. Dai, and Y. Yao, "Prediction of resilient modulus of compacted cohesive soils in South China," International Journal of Geomechanics, vol. 19, no. 7, article 04019068, 2019.

[13] P. Kettil, B. Lenhof, K. Runesson, and N.-E. Wiberg, "Simulation of inelastic deformation in road structures due to cyclic mechanical and thermal loads," Computers \& Structures, vol. 85, no. 1-2, pp. 59-70, 2007.

[14] X. Tan, W. Chen, H. Tian, and J. Cao, "Water flow and heat transport including ice/water phase change in porous media: numerical simulation and application," Cold Regions Science and Technology, vol. 68, no. 1-2, pp. 74-84, 2011.

[15] C. G. Koh, J. S. Y. Ong, D. K. H. Chua, and J. Feng, "Moving element method for train-track dynamics," International Journal for Numerical Methods in Engineering, vol. 56, no. 11, pp. 1549-1567, 2003.
[16] K. M. Rasmussen, S. R. K. Nielsen, and P. H. Kirkegaard, "Boundary element method solution in the time domain for a moving time-dependent force," Computers \& Structures, vol. 79, no. 7, pp. 691-701, 2001.

[17] P. Galvín, A. Romero, and J. Domínguez, "Fully threedimensional analysis of high-speed train-track-soilstructure dynamic interaction," Journal of Sound and Vibration, vol. 329, no. 24, pp. 5147-5163, 2010.

[18] P. A. Costa, R. Calçada, and A. S. Cardoso, "Track-ground vibrations induced by railway traffic: in-situ measurements and validation of a $2.5 \mathrm{~d}$ fem-bem model," Soil Dynamics and Earthquake Engineering, vol. 32, no. 1, pp. 111-128, 2012.

[19] Z. Lu, Z. Hu, H. Yao, J. Liu, and Y. Zhan, "An analytical method for evaluating highway embankment responses with consideration of dynamic wheel-pavement interactions," Soil Dynamics and Earthquake Engineering, vol. 83, pp. 135-147, 2016.

[20] C. L. Monismith, N. Ogawa, and C. R. Freeme, "Permanent deformation characteristics of subgrade soils due to repeated loading," Geotechnical Engineering, vol. 537, pp. 1-17, 1975.

[21] D. Li and E. T. Selig, "Cumulative plastic deformation for finegrained subgrade soils," Journal of Geotechnical Engineering, vol. 122, no. 12, pp. 1006-1013, 1996.

[22] H. Ding, Y. Yang, L.-Q. Chen, and S.-P. Yang, "Vibration of vehicle-pavement coupled system based on a Timoshenko beam on a nonlinear foundation," Journal of Sound and Vibration, vol. 333, no. 24, pp. 6623-6636, 2014.

[23] Z. J. Shen, "Earth pressure of clay based on effective consolidation stress theory," Chinese Journal of Geotechnical Engineering, vol. 22, no. 3, pp. 353-356, 2000. 


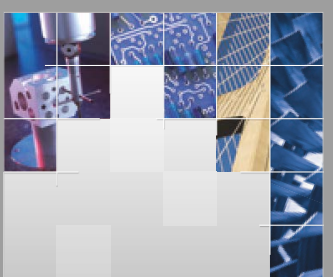

\section{Enfincering}
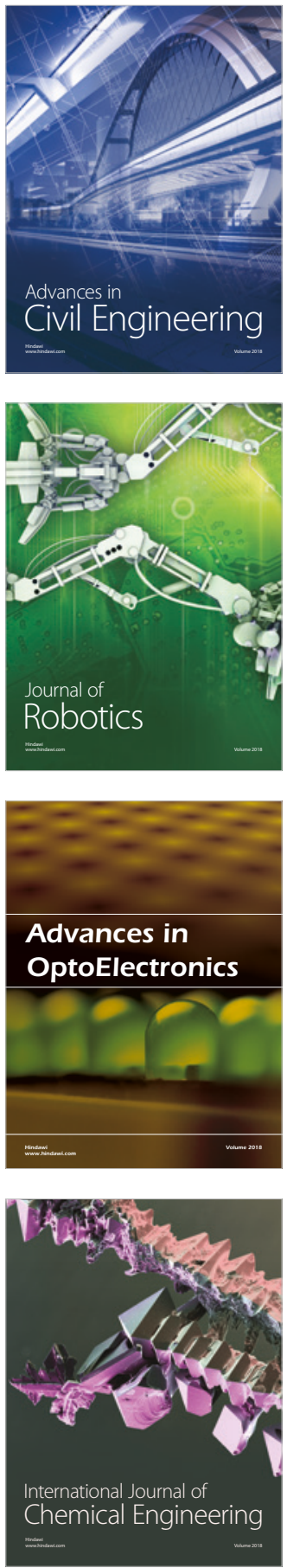

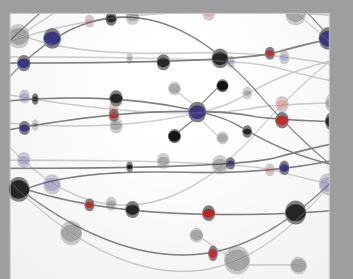

\section{Rotating \\ Machinery}

The Scientific World Journal

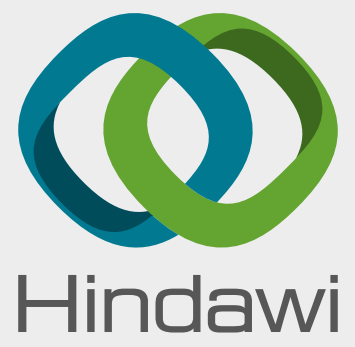

Submit your manuscripts at

www.hindawi.com
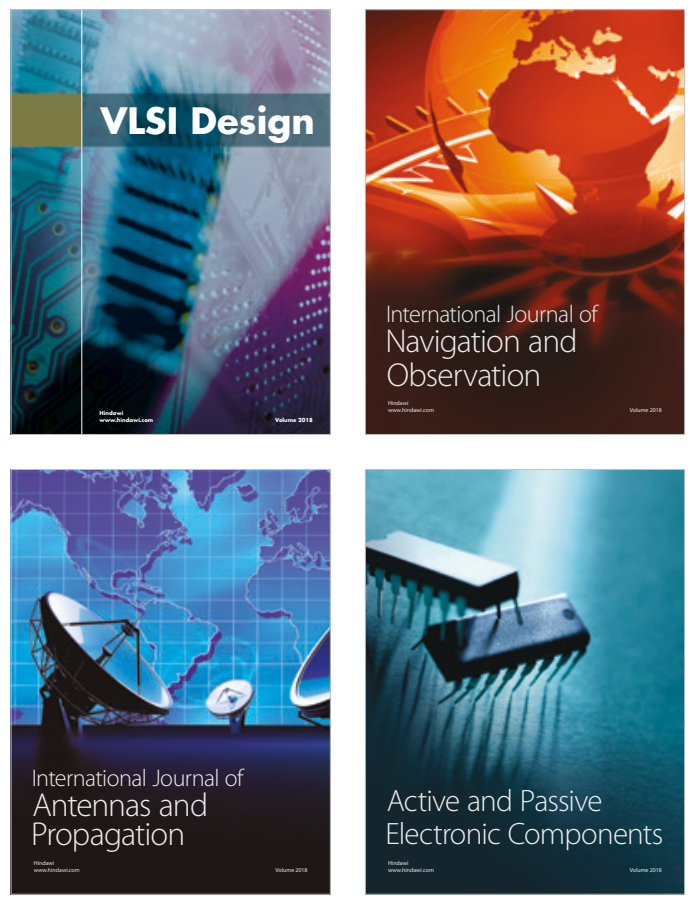
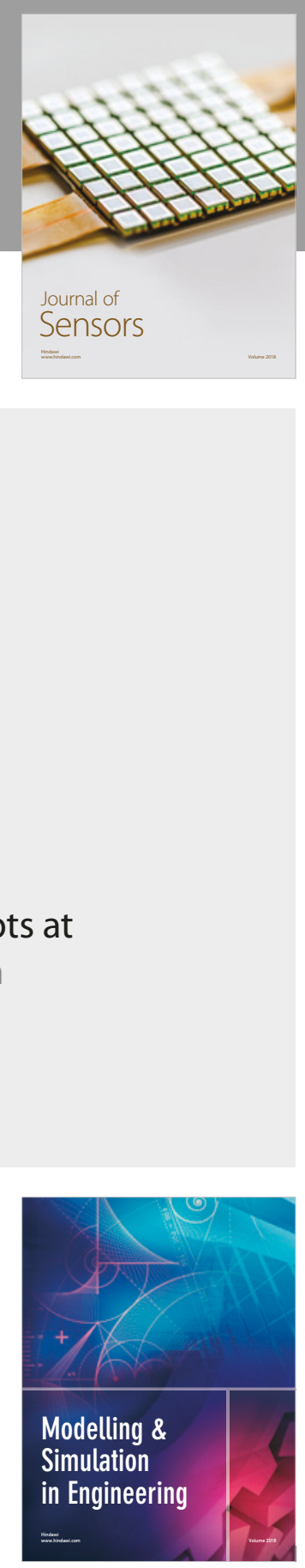

\section{Advances \\ Multimedia}
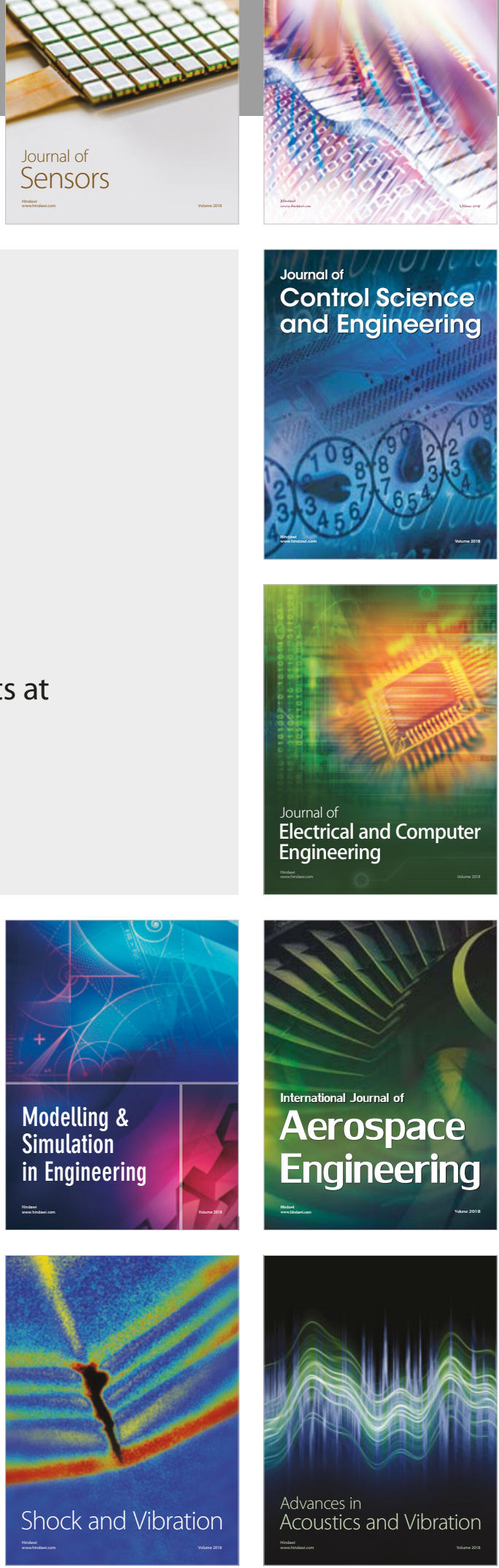